\title{
Stochastic Growth Models with No Discounting ${ }^{\#}$
}

\author{
Karel Sladký
}

\section{Introduction and Notation}

Optimal Growth Economics, originated by works of Frank P. Ramsey in the late twenties of the 20th century, is a relatively separated part of traditional macroeconomics. The heart of the seminal paper of F. P. Ramsey (1928) on mathematical theory of saving is an economy producing output from labour and capital and the task is to decide how to divide production between consumption and capital accumulation to maximize the global utility of the consumers. Ramsey's results were revisited and significantly extended only after almost thirty years by Cass (1965), Koopmans (1965) and Samuelson (1965) and at present the Ramsey model can be considered, along with the Solow model and overlapping generations model (see e.g. Solow, 1998), as one of the three most significant tools for the dynamic general equilibrium model in modern macroeconomics. Except of the Solow book (1998) this problem is also touched with for example in (Blanchard - Fischer, 1989; Sardar, 2001).

The respective mathematical model of the original Ramsey problem in discretetime setting (see also Dana - Le Van, 2003; Heer - Maußer, 2005; Stokey - Lukas, 1989) can be formulated as follows:

We consider at discrete-time points $t=0,1, \ldots$ an economy in which at each time $t$ there are $L_{t}$ identical consumers with consumption $c_{t}$ per consumer. The number of consumers grow very slowly in time, i.e. $L_{t}=L_{0}(1+n)^{t}$ for $t=0,1, \ldots$ with $\alpha:=(1+n) \approx 1$. The economy produces at times $t=0,1, \ldots$ gross output $\tilde{Y}_{t}$ using only two inputs: capital $K_{t}$ and labour $L_{t}=L_{0}(1+n)^{t}=\alpha^{t} L_{0}$. A production function $F\left(K_{t}, L_{t}\right)$ relates input to output, i.e.

$$
\tilde{Y}_{t}=F\left(K_{t}, L_{t}\right) \text { with } K_{0}>0, L_{0}>0 \text { given. }
$$

In each period the demand for (total) consumption $c_{t} L_{t}$ and for gross investment cannot be greater than production, i.e.

$$
c_{t} L_{t}+I_{t} \leq \tilde{Y}_{t}=F\left(K_{t}, L_{t}\right)
$$

This research was supported by the Czech Science Foundation under Grants 402/05/0115 and 402/06/0990.

Ing. Karel Sladký, CSc. - research fellow; Department of Econometrics, Institute of Information Theory and Automation of the Academy of Sciences of the Czech Republic, Pod Vodárenskou věži 4, 18208 Prague 8, Czech Republic; <sladky@utia.cas.cz>. 
gross investment $I_{t}$ is used in whole (along with the depreciated capital $K_{t}$ ) for the capital $K_{t+1}$. In addition, capital is assumed to depreciate at a constant rate $\delta \in(0,1)$, so capital related to gross investment at time $t+1$ is equal to

$$
K_{t+1}=(1-\delta) K_{t}+I_{t} \text {. }
$$

Denoting by $k_{t}:=K_{t} / L_{t}$ the capital per consumer at time $t$, and similarly by $y_{t}:=Y_{t} / L_{t}=F\left(k_{t}, 1\right)$ the output per consumer at time $t$ (note that $F(\cdot, \cdot)$ is assumed to be homogeneous of degree one, i.e. $F(\theta K, \theta L)=\theta F(K, L)$ for any $\theta \in R)$, from (2), (3) we get

$$
c_{t}+k_{t+1}-(1-\delta) k_{t} \leq y_{t}=F\left(k_{t}, 1\right),
$$

and if we define the function $f(\cdot)$ by $f(k):=F(k, 1)+(1-\delta) k$ then (4) can be written as

$$
c_{t}+k_{t+1} \leq y_{t}=f\left(k_{t}\right)
$$

where $c_{t} \geq 0, k_{t} \geq 0$ with $k_{0}>0$ given, and $y_{t}$ is the total output at time $t$.

Preferences over consumption of the considered number $L_{t}=\alpha^{t} L_{0}$ consumers are taken to be of the form

$$
\sum_{t=0}^{T} \beta^{t} L_{t} \cdot u\left(c_{t}\right)=L_{0} \sum_{t=0}^{T}(\alpha \beta)^{t} u\left(c_{t}\right) \quad \text { for a finite or infinite time horizon } T,
$$

where $u(\cdot)$ is instantaneous utility function and $\beta<1$ (close to unity) is a given discount factor.

The problem is to find the rule how to split production between consumption and capital accumulation that maximizes global utility of the consumers for a finite or infinite time horizon $T$.

Throughout this note we make the following general assumption.

AS 0. The considered discount factor $\beta=\alpha^{-1}$.

\section{Remark 1.}

Assumption AS 0 can be justified since $\alpha:=(1+n)>1$ is very close to one and the discount factor $\beta<1$ close to one does not significantly prefer values obtained in the "near future" and its precise value depends on the choice of the decision maker. As we shall see later, specific choice of the discount factor $\beta$ such that $\alpha \beta=1$ considerably simplifies our further analysis.

Under AS 0 from (6) we get

$$
\sum_{t=0}^{T} \beta^{t} L_{t} \cdot u\left(c_{t}\right)=L_{0} \cdot U_{k_{0}}(T),
$$


where

$$
U_{k_{0}}(T):=\sum_{t=0}^{T} u\left(c_{t}\right) \text { for } T=1,2, \ldots,
$$

is the global utility per consumer obtained up to time $T$. Observe that for $T \rightarrow \infty$ the value $U_{k_{0}}(T)$ is typically infinite. To this end we introduce the mean global utility as

$$
g:=\liminf _{T \rightarrow \infty} T^{-1} \cdot U_{k_{0}}(T)
$$

(we show that under our further assumptions $g$ is independent of the initial capital $k_{0}$ ).

In the above formulation we assume that the production function $f(k)$ and the consumption function $u(c)$ fulfil some standard assumptions on production and consumption functions, in particular, that:

AS 1. The function $u(c): R^{+} \rightarrow R^{+}$is twice continuously differentiable and satisfies $u(0)=0$. Moreover, $u(c)$ is strictly increasing and concave (i.e., its derivatives satisfy $u^{\prime}(\cdot)>0$ and $\left.u^{\prime \prime}(\cdot)<0\right)$ with $u^{\prime}(0)=+\infty$ (so-called Inada Condition).

AS 2. The function $f(k): R^{+} \rightarrow R^{+}$is twice continuously differentiable and satisfies $f(0)=0$. Moreover, $f(k)$ is strictly increasing and concave (i.e., its derivatives satisfy $f^{\prime}(\cdot)>0$ and $\left.f^{\prime \prime}(\cdot)<0\right)$ with $f^{\prime}(0)=M<+\infty$, $\lim _{k \rightarrow \infty} f^{\prime}(k)<1$.

Finding a sequence $(k, c)^{T}=\left\{k_{0}, c_{0}, k_{1}, c_{1}, \ldots, k_{T}, c_{T}\right\}$ with a given $k_{0}>0$ maximizing under condition (5) the global utility $U_{k_{0}}(T)$ defined by (8) can be formulated as:

Find

$$
\hat{U}_{k_{0}}(T):=\max _{(k, c)^{T}} \sum_{t=0}^{T} u\left(c_{t}\right) \text { for a given (possibly infinite) time horizon } T,
$$

under the constraints $c_{t}+k_{t+1} \leq f\left(k_{t}\right), c_{t} \geq 0, k_{t} \geq 0$ with $k_{0}>0$ given.

Note that since $u(\cdot), f(\cdot)$ are increasing (cf. assumptions AS 1 and AS 2) it is possible to replace the constraints (5) by

$$
\begin{aligned}
& c_{t}+k_{t+1}=f\left(k_{t}\right), \quad \text { with } f\left(k_{t}\right)=y_{t}, \\
& c_{t} \geq 0, \quad k_{t} \geq 0, \quad k_{0}>0 \text { given, and if } T<+\infty \text { also } k_{T+1}=0 .
\end{aligned}
$$

Hence by (11) the expression for the maximum global utility per consumer can be written as

$$
\hat{U}_{k_{0}}(T)=\max _{k^{T}} \sum_{t=0}^{T} u\left(f\left(k_{t}\right)-k_{t+1}\right) \text { for a finite or infinite time horizon } T,
$$


where $k^{T}=\left\{k_{0}, k_{1}, \ldots, k_{T}\right\}$ and $U_{k_{0}}^{k^{T}}(T):=\sum_{t=0}^{T} u\left(f\left(k_{t}\right)-k_{t+1}\right)$.

Observe that in virtue of assumption AS 2 and (11) it holds:

\section{Remark 2.}

i) If $f^{\prime}(0) \leq 1$ (and hence $f^{\prime}(k)<1$ for all $k>0$ ), then by (11) every sequence $\left\{k_{0}, k_{1}, \ldots, k_{t}, \ldots\right\}$ must be decreasing and $\lim _{t \rightarrow \infty} k_{t}=0$.

ii) If $f^{\prime}(0)>1$ (and hence, since $\lim _{k \rightarrow \infty} f^{\prime}(k)<1$, there exists some $k^{\prime}$ such that $f^{\prime}(k)<1$ for all $\left.k>k^{\prime}\right)$, then there exists some $k^{*}>0$ such that $f\left(k^{*}\right)=k^{*}$ and some $k_{m} \in\left(0, k^{*}\right)$ such that $f\left(k_{m}\right)-k_{m}=\max _{k}[f(k)-k]$.

Supposing that $k_{0}>k^{*}$ then elements of the sequence $\left\{k_{0}, k_{1}, \ldots, k_{t}, \ldots\right\}$ must be decreasing for all $k_{t}>k^{*}$. Furthermore, if for some $t=t_{\ell}$ it holds $k_{t_{\ell}}<k^{*}$ then $k_{t}<k^{*}$ for all $t \geq t_{\ell}$, but $\left\{k_{t}, t \geq t_{\ell}\right\}$ need not be monotonous. However, in any case $k_{t} \leq k_{\max }=\max \left(k_{0}, k^{*}\right)$ and $f\left(k_{t}\right) \leq f\left(k_{\max }\right)=: y_{\max }$ for all $t=0,1, \ldots$.

iii) In case that $k_{0}^{\prime}>k_{0}>0$ then $\hat{U}_{k_{0}^{\prime}}(T)>\hat{U}_{k_{0}}(T)$. This can be easily verified since if we start with initial capital $k_{0}^{\prime}>k_{0}$, and by selecting consumption at time 0 such that $c_{0}^{\prime}+k_{1}=f\left(k_{0}^{\prime}\right)>c_{0}+k_{1}=f\left(k_{0}\right)$ (recall that $f\left(k_{0}^{\prime}\right)>f\left(k_{0}\right)$ and $u(\cdot)$ is increasing) and following for every $t>0$ decisions given by $k^{T} \equiv\left(k_{0}, k_{1}, \ldots, k_{T}\right)$ (the sequence of capital stocks yielding $\hat{U}_{k_{0}}(T)$ in (13)), then $u\left(f\left(k_{0}^{\prime}\right)-k_{1}\right)>u\left(f\left(k_{0}\right)-k_{1}\right)$ and $u\left(f\left(k_{t}^{\prime}\right)-k_{t+1}^{\prime}\right)$ with $k_{t}^{\prime} \equiv k_{t}$ for all $\left.t \geq 1\right)$.

\section{The Growth Model under Random Shocks}

Up to now we have assumed that for a given $k_{t}$ the total output is given by $y_{t}=f\left(k_{t}\right)$. To include random shocks or imprecisions into the model, we shall assume that for a given value of $k_{t}$ we obtain the output $y_{t}$ only with known probability $p\left(k_{t}\right) \equiv p\left(k_{t} ; 0\right)<1$, hence with probability $\bar{p}\left(k_{t}\right)=1-p\left(k_{t}\right)$ the total output will be different from $y_{t}=f\left(k_{t}\right)$ and can attain maximal and minimal possible values $f_{\max }\left(k_{t}\right)$ and $f_{\min }\left(k_{t}\right)$ respectively (of course, we assume that assumptions AS 2 also hold for $f_{\max }(\cdot)$ and $\left.f_{\min }(\cdot)\right)$. Since (cf. assumption AS 1) instantaneous utility function $u(\cdot)$ is increasing, on replacing the production function $f\left(k_{t}\right)$ by $f_{\max }\left(k_{t}\right)$ and $f_{\min }\left(k_{t}\right)$ we obtain upper or lower bounds on the total output at time $t$ and also, for fixed values of $k_{t}$, also the upper and lower bounds on the maximal global 
utility of the consumers respectively. This approach is relatively simple, but ignores a lot of information and yields only a very rough bounds on optimal values.

Obviously, significantly better results can be obtained if we replace the rough estimates of $y_{t}$ generated by upper and lower bounds $f_{\max }\left(k_{t}\right)$ and $f_{\min }\left(k_{t}\right)$ by a more detailed information on the (random) output $y_{t}$ generated by the capital $k_{t}$.

Recall that by Remark 2 ii) the values of $k_{t}, y_{t}=f\left(k_{t}\right)$ (and hence also $c_{t}$ ) are bounded by $k_{\max }, y_{\max }$ respectively with $f_{\max }():.=y_{\max }$. To this end we shall assume that in (5), (11)

$$
y_{t}=Z_{t} f\left(k_{t}\right) \text {, where } Z=\left\{Z_{t}, t=0,1, \ldots\right\} \text { is a random process. }
$$

In the literature (cf. Heer - Maußer, 2005; Majumdar - Mitra - Nishinmura, 2000, or the monograph Stokey - Lukas, 1989) it is usually assumed that $Z$ is a Markov process (in general with state space $R$ ) or an autoregressive process. Moreover, we assume that the decision maker can observe the current values of the total output $y_{t}$ and then select the value of $k_{t+1}$. Such an extension well corresponds to the models introduced and studied in (Stokey - Lukas, 1989) and also in (Heer - Maußer, 2005; Majumdar - Mitra - Nishinmura, 2000). Unfortunately, assuming that $Z$ is a Markov process with compact state space $R$ then a rigorous treatment of the model given by (11) - (13) requires a very sophisticated mathematics (see Blackwell, 1965 or Stokey Lukas, 1989) and is not suitable for numerical computation. To make the model computationally tractable, similarly as in Sladký (2006), we shall approximate the time development of our system governed by (11), (12) (with $f(\cdot):=f_{\max }(\cdot)$ ) by a discretized model with finite state space.

To this end, we shall assume that the values of $c_{t}, k_{t}$, and $y_{t}$ take on only a finite number of discrete values. In particular, we assume that for sufficiently small $\Delta>0$ there exists nonnegative integers $\bar{c}_{t}, \bar{k}_{t}$, and $\bar{y}_{t}$ such that for every $t=0,1, \ldots$ it holds: $\bar{c}_{t} \Delta=c_{t}, \quad \bar{k}_{t} \Delta=k_{t}$, and $\bar{y}_{t} \Delta=y_{t}$ with $\quad \bar{k}_{t} \leq K:=k_{\max } / \Delta$ and similarly $\bar{y}_{t} \leq Y:=y_{\max } / \Delta$. Let elements of $\bar{k}_{t}$ be labelled by integers from $I_{K}=\{0,1, \ldots, K\}$ and elements of $\bar{y}_{t}$ by integers from $I_{Y}=\{0,1, \ldots, Y\}$. Hence for the total output $y_{t}$ generated by the "randomized" production function we get for $\ell=0,1,2, \ldots, L$ (recall that we have set $f(\cdot):=f_{\text {max }}(\cdot)$ )

$\bar{y}_{t}=f\left(\bar{k}_{t} \Delta\right) / \Delta-\ell \quad$ with known probability $p\left(\bar{k}_{t} ; \ell\right) ;$ obviously, $\sum_{\ell=0}^{L} p\left(\bar{k}_{t} ; \ell\right)=1$,

and let (the row vector) $p\left(\bar{k}_{t}\right)=\left[p\left(\bar{k}_{t} ; 0\right), p\left(\bar{k}_{t} ; 1\right), \ldots, p\left(\bar{k}_{t} ; L\right)\right]$. 
We shall assume that $p\left(\bar{k}_{t}\right)$ is "close" to $p\left(\bar{k}_{t+1}\right)$ for every $\bar{k}_{t}$, i.e. assume existence of some $\tilde{\Delta}>0$ such that $\left|p\left(\bar{k}_{t+1} ; \ell\right)-p\left(\bar{k}_{t} ; \ell\right)\right|<\tilde{\Delta}$ for every $\ell=1, \ldots, L$ and $\bar{k}_{t}=1, \ldots, K$.

If the (random) total output at time $t \bar{y}_{t}=\bar{y}$ then the decision maker have option to invest for the next time point the capital $k_{t+1}=\bar{k}_{t+1} \Delta$ where $\bar{k}_{t+1}=\bar{g}_{t}, \ldots, \bar{y}_{t}$ (with given $\left.\bar{g}_{t}=0,1, \ldots, f_{\max }\left(\bar{k}_{t}\right)\right)$, and hence $u\left(\left(\bar{y}-\bar{k}_{t+1}\right) \Delta\right)$ is the instantaneous utility accrued at time $t$ to the global utility of a customer. In accordance with decision $d$ taken at time $t$ if the output $\bar{y}_{t}=\bar{y}$, at the next time $t+1$ capital $\bar{k}_{t+1}$ will be available, see also the following diagram

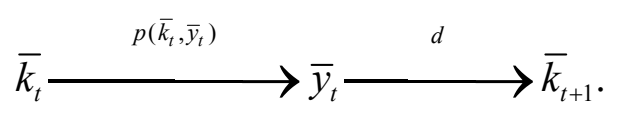

Using the above discretization and taking decisions with respect to the current states, the development of the economy over time can be well described by a (highly structured) Markov reward chain $X=\left\{X_{\tau}, \tau=0,1, \ldots\right\}$ with finite state space $I=I_{K} \cup I_{Y}$ (where $\left.I_{K} \cap I_{Y}=\varnothing\right)$, transition probabilities $p\left(\bar{k}_{t} ; \bar{y}_{t}\right)=p_{i j}$, for $i=\bar{k}_{t} \in I_{K}, j=\bar{y}_{t} \in I_{Y}$, and a "non-random" transition from state $j=\bar{y}_{t} \in I_{Y}$ to state $\ell=\bar{k}_{t} \in I_{K}$ associated with one-stage reward $r_{j \ell}=u\left(\left(\bar{y}_{t}-\bar{k}_{t+1}\right) \Delta\right)$. Observe that actually "two transitions" of the Markov chain $X=\left\{X_{\tau}, \tau=0,1, \ldots\right\}$ occur within one-time period of the considered economy model and the one-stage reward is accrued only in even transitions. Hence the global utility (i.e. the total reward of the Markov chain $X) \quad U_{k_{0}}(T)=\mathrm{E}\left\{\sum_{t=1}^{T} r_{X_{2 t-1}, X_{2 t}} \mid X_{0}=\bar{k}_{0}\right\} \quad$ (the symbol $\mathrm{E}$ is reserved for expectation).

\section{Extension of the Stochastic Growth Model}

Up to now we have assumed that the probability vector $p\left(\bar{k}_{t}\right)$ cannot be influenced by the decision maker. Now we extend the model in such a way that $p\left(\bar{k}_{t}\right)$ will be replaced by a family of vectors $p\left(\bar{k}_{t}, d\left(\bar{k}_{t}\right)\right)$ for $d\left(\bar{k}_{t}\right)=1,2, \ldots, D$ depending on the decision taken in state $\bar{k}_{t}$. Moreover, some cost, denoted $c\left(d\left(\bar{k}_{t}\right)\right)$, will be accrued to this decision.

Moreover, we shall assume that decision $d$ (taken if at time $t$ the output $\bar{y}_{t}=\bar{y}$ ) assigns the desired values of capital only with some probability, i.e. there is a set of feasible decisions $d\left(\bar{y}_{t}\right)=1,2, \ldots, D$ each of them assigns the value $\bar{k}=1,2, \ldots, K$ of capital $\bar{k}_{t+1}$ with a given probability $p\left(\bar{y}_{t} ; \bar{k}, d\left(\bar{y}_{t}\right)\right) \leq 1$. Moreover, the complete 
information is contained in the vector of transition probabilities $p\left(\bar{y}_{t}, d\left(\bar{y}_{t}\right)\right)=\left[p\left(\bar{y}_{t} ; 1, d\left(\bar{y}_{t}\right)\right), p\left(\bar{y}_{t} ; 2, d\left(\bar{y}_{t}\right)\right), \ldots, p\left(\bar{y}_{t} ; K, d\left(\bar{y}_{t}\right)\right)\right]$.

We shall assume that $p\left(\bar{k}_{t}, d\right)$ (resp. $\left.p\left(\bar{y}_{t}, d\right)\right)$ is "close" to $p\left(\bar{k}_{t+1}, d\right)$ (resp. $p\left(\bar{y}_{t+1}, d\right)$ ) for every $\bar{k}_{t}$ (resp. $\left.\bar{y}_{t}\right)$, i.e. we assume existence of some $\tilde{\Delta}>0$ such that for every $\ell=1, \ldots, L$ and $\bar{k}_{t}=1, \ldots, K\left|p\left(\bar{k}_{t+1} ; \ell, d\right)-p\left(\bar{k}_{t} ; \ell, d\right)\right|<\tilde{\Delta}$ and similarly for every $\ell=1, \ldots, D$ and $\bar{y}_{t}=1, \ldots, K \quad\left|p\left(\bar{y}_{t+1} ; \ell, d\right)-p\left(\bar{y}_{t} ; \ell, d\right)\right|<\tilde{\Delta}$. So the time development is given by the following diagram

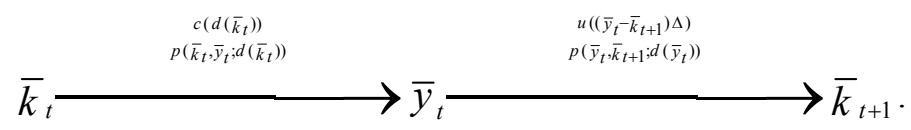

In contrast to the previous model transition from certain state $\bar{y}_{t} \in I_{Y}$ to state $\bar{k}_{t+1} \in I_{K}$ is nondeterministic and probability of reaching a specific value of the (random) variable $\bar{k}_{t+1}$ depends on the selected decision $d\left(\bar{y}_{t}\right)$.

\section{Formulation in Terms of Stochastic Dynamic Programming}

The above model can be treated as a highly structured Markov decision chain with finite state space $I=I_{1} \cup I_{2}$ (with $I_{1} \cap I_{2}=\varnothing$ ), finite set $D_{i}=\{0,1, \ldots, d(i)\}$ of possible decisions (actions) in state $i \in I$ and the following transition and reward structure

$p_{i j}(a)$ : transition probability from $i \rightarrow j(i, j \in I)$ if action $a \in D_{i}$ is selected,

$r_{i j}$ : one-stage reward for a transition from $i \rightarrow j$, with

$r_{i j}=u((i-j) \Delta)$ if $i \in I_{2}$ and $j \in I_{1}$,

$r_{i j}=c(a)$ if $i \in I_{1}$ and $j \in I_{2}$, and action $a$ is selected,

$r_{i}(a)$ : expected value of the one-stage rewards incurred in state $i$ if decision (or action)

$a \in D_{i}$ is selected in state $i$; in particular $r_{i}(a)=\sum_{j \in I} p_{i j}(a) \cdot r_{i j}$.

Policy controlling the chain, say $\pi$, is a rule how to select actions in each state. Policy $\pi$ is then fully identified by a sequence $\left\{d_{\tau}, \tau=0,1, \ldots\right\}$ of decision vectors (of dimension $K$ and $Y$ in odd and even steps respectively) whose $i$-th element $d_{\tau}(i) \in D_{i}$ identifies the action taken if $X_{\tau}=i$. If we restrict on stationary policies, i.e. the rules selecting actions only with respect to the current state of Markov chain $X$, then policy $\pi$ is fully determined by $d_{t} \equiv d$. Observe that decision vector $d$ then completely identifies the transition probability matrix $P(d)$ and the $i$-th row of $P(d)$ has elements $p_{i 1}(d(i)), \ldots, p_{i N}(d(i))$. Similarly, $r(d)$ is a (column) vector of onestage expected rewards (i.e. $i$-th element of $r(d)$ is equal to $\left.r_{i}(d(i))\right)$. 
In what follows we assume that for an arbitrary policy the considered Markov chain contains a single class of recurrent states guaranteed by the following:

AS 3. There exists state $i_{0} \in I$ that is accessible from any state $i \in I$ for any stationary policy.

Let the vector $U^{\pi}(\tau)$ (with elements $\left.U_{i}^{\pi}(\tau)\right)$ denote expectation of the (random) global utility $\xi_{\tau}$ received in the $\tau$ next transitions of the considered Markov chain $X$ if policy $\pi=\left(d_{\tau}\right)$ is followed, given the initial state $X_{0}=i$. In particular, for the elements of $U^{\pi}(\tau)$ we have $U_{i}^{\pi}(\tau)=\mathrm{E}_{i}^{\pi}\left[\xi_{\tau}\right]$ where $\xi_{\tau}=\sum_{k=0}^{\tau-1} r_{X_{k}, X_{k+1}}$ and $\mathrm{E}_{i}^{\pi}$ is the expectation if $X_{0}=i$ and policy $\pi=\left(d_{\tau}\right)$ is followed. Then obviously

$$
U_{i}^{\pi}(\tau+1)=r_{i}\left(d_{\tau}(i)\right)+\sum_{j \in I} p_{i j}\left(d_{\tau}(i)\right) \cdot U_{j}^{\pi}(\tau), \quad i \in I
$$

and for $t$ (or $\tau$ ) tending to infinity it can be shown (see e.g. Puterman, 1994; Ross, 1970) that under AS 3 the growth of $U^{\pi}(\tau)$ is linear in time, i.e. $\lim _{\tau \rightarrow \infty} U_{i}^{\pi}(\tau) \sim g^{\pi} \tau$, and for stationary policy $\pi=\left(d_{\tau}\right)$ from (16) it is possible to conclude existence of $w_{i}^{\pi}$ 's such that

$$
g^{\pi}+w_{i}^{\pi}=r_{i}(d(i))+\sum_{j \in I} p_{i j}(d(i)) \cdot w_{j}^{\pi}, \quad i \in I,
$$

where $g^{\pi}$ is unique and $w_{i}^{\pi}$ 's (for $i \in I$ ) are unique up to an additive constant (for details see e.g. Puterman, 1994; Ross, 1970). If $\hat{\pi}^{T}$ is (in general nonstationary) policy maximizing the values $U_{i}^{\pi}(T)$ for the fixed time horizon $T$ then

$$
U_{i}^{\hat{\pi}^{\tau}}(\tau)=\max _{d \in D_{i}}\left[r_{i}\left(d_{\tau}(i)\right)+\sum_{j \in I} p_{i j}\left(d_{\tau}(i)\right) \cdot U_{j}^{\hat{\pi}^{\tau-1}}(\tau-1)\right], \text { for } \tau=T, T-1, \ldots, 1,0 .
$$

Furthermore, in analogy of (17) we get $\lim _{T \rightarrow \infty} U_{i}^{\star}(T) \sim g^{\star} T$, along with

$$
g^{\hat{\pi}}+w_{i}^{\hat{\pi}}=\max _{d \in D_{i}}\left[r_{i}(d(i))+\sum_{j \in I} p_{i j}(d(i)) \cdot w_{j}^{\hat{\pi}}\right], \quad i \in I
$$

where $g^{\hat{\pi}}$ is the (unique) maximal mean reward and $w_{i}^{\hat{\pi}}$ 's (for $i \in I$ ) are unique up to an additive constant (for details, see e.g. Puterman, 1994; Ross, 1970).

\section{Computation of Optimal Policies}

In case that the time horizon $T$ is finite, it is necessary to calculate (backwards) the dynamic programming recursion according to (16). Considering the infinite time horizon (i.e. if $T \rightarrow \infty$ ), finding a solution of (17) is in some aspects much easier (optimal policy can be found in the class of stationary policies, i.e. policies selecting actions only with respect to the current state of Markov chain) and can be performed 
either by value iterations (successive approximations) or by policy iterations. For more details see e.g. Puterman (1994) or Ross (1970).

Algorithm 1 (Policy iteration - Howard, 1960)

Step 0 . Select arbitrary policy, say $d^{(0)}$.

Step 1 - Policy evaluation. For stationary policy $d^{(n)}$ find $w=w\left(d^{(n)}\right)$ as a solution of

$$
g e+w=r\left(d^{(n)}\right)+P\left(d^{(n)}\right) w,
$$

( $e$ denotes a unit vector).

Step 2 - Policy improvement. For a given $w\left(d^{(n)}\right)$ find policy $d^{(n+1)}$ such that

$$
r\left(d^{(n+1)}\right)+P\left(d^{(n+1)}\right) w\left(d^{(n)}\right)=\max _{d \in D}\left[r(f)+P(d) w\left(d^{(n)}\right)\right] .
$$

If there exists $d^{(n+1)}=d^{(n)}$, then stop and policy $d^{(n)}$ is an optimal policy with mean reward $g^{\hat{\pi}}$, else go to Step 1 .

Algorithm 2 (Value iteration - Bellman, 1957)

Select $v^{(0)}=0$, choose some (sufficiently small) $\varepsilon>0$, and iterate

$$
v^{(n+1)}:=\max _{d \in D}\left[r(d)+P(d) v^{(n)}\right] \quad \text { for } n=0,1, \ldots
$$

If $\left\|v^{(n+1)}-v^{(n)}\right\|<\varepsilon$ then stop, and $g^{(n)}=n^{-1} v^{(n)}$ is a good approximation of the maximum mean reward $g^{\hat{\pi}}(\|\cdot\|$ denotes standard supremum norm).

Remark. Observe that $v^{(n)}$ 's are identical with $U^{\pi}(n)$ if policy $\pi$ is identified by the decision vectors generated by Algorithm 2 .

Algorithm 3 (Value iteration (modified) - White, 1963; Odoni, 1969; Sladký, 1969)

Select $w^{(0)}=0$, choose some (sufficiently small) $\varepsilon>0$, set $w_{N}^{(n)} \equiv 0$ for $n=0,1, \ldots$, and iterate

$$
w^{(n+1)}:=\max _{d \in D}\left[r(d)+P(d) w^{(n)}\right] .
$$

Then

$$
\max _{i \in I}\left[w_{i}^{(n+1)}-w_{i}^{(n)}\right], \quad \text { resp. } \quad \min _{i \in I}\left[w_{i}^{(n+1)}-w_{i}^{(n)}\right],
$$

is an upper (resp. lower) bound on maximum mean reward $g^{\hat{\pi}}$ converging monotonously to $g^{\hat{\pi}}$. If $\left\|w^{(n+1)}-w^{(n)}\right\|<\varepsilon$ then stop. 


\section{References}

[1] BELLMAN, R. (1957). Dynamic Programming. Princeton : Princeton University Press, 1957.

[2] BLACKWELL, D. (1965). Discounted dynamic programming. The Annals of Mathematical Statistics, 1965, vol. 36, no. 1, pp. 226-235.

[3] BLANCHARD, O. J.; FISCHER, S. (1989). Lectures on Macroeconomics. Boston : MIT Press, 1989.

[4] CASS, D. (1965). Optimum growth in an aggregate model of capital accumulation. Review of Economic Studies, 1965, vol. 32, no. 3, pp. 233-240.

[5] DANA, R. A.; Le VAN, C. (2003). Dynamic Programming in Economics. Dordrecht : Kluwer, 2003.

[6] HEER, B.; MAUßER, A. (2005). Dynamic General Equilibrium Modelling. Berlin : Springer-Verlag, 2005.

[7] HOWARD, R. A. (1960). Dynamic Programming and Markov Processes. Cambridge : MIT Press, 1960.

[8] KOOPMANS, T. C. (1965). On the concept of optimal economic growth. In The Econometric Approach to Development Planning. Amsterdam : North Holland, 1965, pp. 225-287.

[9] ODONI, A. R. (1969). On finding the maximal gain for Markov decision processes. Operations Research, 1969, vol. 17, no. 5, pp. 857-860.

[10] MAJUMDAR, M.; MITRA, T.; NISHIMURA, K. (eds.) (2000). Optimization and Chaos. Berlin : Springer-Verlag, 2000.

[11] PUTERMAN, M. L. (1994). Markov Decision Processes - Discrete Stochastic Dynamic Programming. New York : Wiley, 1994.

[12] RAMSEY, F. P. (1928). A mathematical theory of saving. Economic Journal, 1928, vol. 38, no. 152, pp. 543-559.

[13] ROSS, S. M. (1970). Applied Probability Models with Optimization Applications. San Francisco : Holden-Day, 1970.

[14] SAMUELSON, P. A. (1965). A catenary turnpike theorem involving consumption and the Golden Rule. American Economic Review, 1965, vol. 55, no. 3, pp. 486496.

[15] SARDAR, M. N. I. (2001). Optimal Growth Economics. Amsterdam : North Holland, 2001.

[16] SLADKÝ, K. (1969). O metodě postupných aproximací pro nalezení optimálního řízení markovského řetězce. Kybernetika, 1969, vol. 5, no. 4, pp. 167-176.

[17] SLADKÝ, K. (2006). Approximations in stochastic growth models. In Proceedings of the 24th Internat. Conference Mathematical Methods in Economics 2006, University of West Bohemia, Pilsen 2006, pp. 465-470, CD ROM.

[18] SOLOW, R. M. (1988). Growth Theory: An Exposition. Oxford : Oxford University Press, 1988. 
[19] STOKEY, N. L.; LUKAS, R. E., Jr. (1989). Recursive Methods in Economic Dynamics. Boston : Harvard University Press, 1989.

[20] WHITE, D. J. (1963). Dynamic programming, Markov chains, and the method of successive approximations. Journal of Mathematical Analysis and Applications, 1963, vol. 6, pp. 373-376.

\title{
Stochastické růstové modely bez diskontování
}

\author{
Karel Sladký
}

\begin{abstract}
Abstrakt
V práci je studován Ramseyův růstový model s diskrétním časovým parametrem bez diskontování, jehož chování je zatíženo neurčitostmi modelovanými pomocí markovských procesů. Jsou uvažována různá znáhodnění klasického Ramseyova modelu, diskutována diskretizace stavového prostoru a je ukázáno, jak po provedené diskretizaci je možno vzniklé úlohy formulovat a řešit jako úlohy o nalezení optimálního řízení (vysoce strukturovaného) markovského řetězce s ohodnoceními. Jsou popsány základní algoritmické postupy pro numerické řešení těchto úloh.
\end{abstract}

Klíčová slova: ekonomická dynamika; stochastická verze Ramseyova růstového modelu; Markovské rozhodovací procesy.

\section{Stochastic Growth Models With No Discounting}

\begin{abstract}
In this note, we consider in discrete time the Ramsey growth model without discounting under stochastic uncertainty modelled by Markov processes. To make the model computationally tractable we shall consider finite state approximations of the original model. Properties of policies maximizing mean value of the global utility of consumers over an infinite time horizon, along with algorithmic procedures finding optimal and suboptimal policies, are reported.
\end{abstract}

Key words: economic dynamics; stochastic version of the Ramsey growth model; Markov decision processes.

JEL classification: C61, E21, E22. 